sisters, aged 38 and 48 , have good vision. His mother died at 70 years, never having had any failure of sight, and his father is living, at 73 , with good vision; but his father's sister had double cataract when 70 years old.

$$
\text { Jонn L. DiCkex, A.M., M.D. }
$$

\section{Correction in "A Few Clinical Pictures."}

Ann Arbor, Mich., Feb. 27, 1899.

To the Editor:-In my article published in the JournaL of Feb. 18, 1899, (p. 360), in the report of Case No. 5 the statement is made that "she has had local medical treatment for two yeare with no improvement." Since writing this, the physician who treated the patient before I saw her, and who last saw her about a year before she came to me, informs me that when the patient first came under his observation she was the subject of a marked uterine subinvolution, the fundus reaching as high as the umbilicus. I know the physician to be an accurate observer, and therefore feel it just to say that so far as this condition is concerned. "the local medical treatment" had improved the patient, as involution was complete when she came to my notice. Under report of Case No. 6 , in the eighth line from the bottom, read "interrupted" instead of "inter mitted," and in the sixth line from the bottom, read "hernial" instead of "perineal."

John A. Wessinger, M.D.

\section{ASSOCIATION NEWS.}

American Medical Associatlon.-The American Medical AssoCIATION will hold its next annual meeting in Columbus, Ohio, June 6, 7, 8 and 9, 1899. As customary in connection with these meetings, there will be an exhibit. For this purpose a special building, 190 feet long by 44 feet wide, will be erected adjacent to the State House. It will be well lighted and ventilated, and will be supplied with electric current. The rotunda of the State House will be used for registration, for a post-office, and for endorsing railroad certificates. A wide hallway leads directly from the rotunda into the exhibition hall. The Section meeting-places are all located on the square surrounding the State House. No pains will be spared to make the exhibition hall suit the convenience of those who occupy it. It is the determination of the profession of Ohio to make this meeting surpass all previous meetings of the Assocration, and all indications point to a very large attendance. The exhibitors will thus come in contact with a large number of physicians who are not delegates or permanent members ef the Association, but who will embrace this opportunity of visiting the ASSOCJATrON and of making observa. tions of the various lines of goods represented in the exhibit.

N. R. Coleman, chairman, Sub Com. on Exhibits, 264 E. Town St., Columbus, Ohio.

\section{SOCIETY NEWS.}

Medical Association of Georgia.-The fiftieth annual meeting of this Association will be held in Macon, Ga., on April 19, 1899. Titles of papers should be sent to Dr. R. B. Barron, Macon, Ga.

Kalamazoo Academy of Medicine.--At the regular meeting of the Academy, February 21, Dr. A. H. Rockwell read a paper on "Brachycardia," and Dr. Rush MeNair one on "Cranial Surgery."

Washington Microscopic Society.-At the recent meeting of the Society, Washington, D. C., Dr. H. H. Doubleday read a paper entitled "The Psychic Life of Micro-organisms." An interesting discussion followed.

Conference for Prophylaxis of Venereal Diseases.-An internationa sonference to study and discuss measures to arrest the spread of syphilis and venereal diseases, will be held in Brussels in the flrst two weeke of next September.-Semaine Méd., February 1.

Luzerne County Medical Society.-At the recent meeting of this Society, Wilkesbarre, Pa., Dr. L. H. Taylor read a paper on "Mastoid Diseases." The discussion was led by Dr. McFadden. The next meeting will be held March 15, when Dr. Barton of Plains will read a paper on "Puerperal Sepsis."

Toledo Medical Association.--At the meeting February 24, an address was delivered by Dr. Henage Gibbes of Detroit, assisted by Dr. E. H. Troy, on "Inflammatory and Tubercular Phthisis," illustrated with lantern slides on pathologic tissue. A banquet at the University Club followed.

National Sanitary Association.-This association, in session in New York City, February 5 and 6, will meet in A tlanta, Ga., in October. The following officers were elected: Charles S. Benedict, New York, president; T. B. Sales, Raleigh, S. C., first vice-president; Andrew Young, Chicago, second vicepresident: Eugene Monteith, A tlanta, secretary and treasurer.

American Neurological Association.-At a meeting of the Council of the Association held in Philadelphia recently, it was decided to hold the next annual meeting of the Association at Atlantic City, N. J., on June 14, 15 and 16 . The president is Dr. James Hendrie Lloyd, Philadelphia, and the secretary and treasurer, Dr. G. M. Hammond of New York.

New York County Medico-Pharmaceutical League.- This new association was organized February 24, in New York City, its object being "the encouragement of operations at home where practicable, the regulation of lodge-contracting, of dispenearies, hospitals and other medical charities, and the discussion and regulation of other matters of $m$ utual interest to the medical and pharmaceutical professions."

International Congress of Insurance Medical Examiners.-The first international congress of physicians connected with life and accident insurance companies will convene at Brussels, Sept. 25 to 30,1899 . Among the subjects announced for discussion, we note: Insurability in glycosuria, albuminuria, syphilis, neurasthenia, progressive paralysis, traumatic neuroses; the neces. sity of a uniform formula for examination, professional secrecy and the insurance companies.

Wilson Medical Society.-The annual meeting of this Society, an inside organization of Jefferson Medical College, formed some years ago in honor of, and fostered with tender care by Prof. J. C. Wilson, was held February 21, in Philadelphia, Pa. S. Macy Cowgill, president of the Society, acted as toastmaster, toasts being responded to by Prof. J. C. Wilson, F. X. Dereum, H. A. Hare, H. A. Wilson, W. M. L. Coplin, and E. P. Davis.

Washington Medical Society.-At the recent meeting of this Society, Washington, D. C., Dr. A. F. A. King read a paper on "The Mosquito and the Malarial Parasite." Dr. C. L. Allen reported a case of edema in hemiplegia and a case illus. trating early degeneration of the pyramidal tracts, as shown by the Marchi method. Dr. W. Prentise read a paper on "Bermuda as a Winter Resort." $\mathrm{He}$ illustrated his subject by lantern-sides and specimens of natural history.

Lackawanna County Medical Society.-This Society recently held its twentieth annual dinner at Scranton, Pa. C. L. Frey was toastmaster and toasts were responded to as follows: "Mythical Medicine," John C. Bateson; "Medical Education in the United States," L. S. Barnes ; "The Doctor at War," Walter M. Reedy ; "Medical Education Abroad," L. Wehlau ; "Famous Men in Medicine," R. H. Gibbons; "Our Absent Members," D. A. Capwell ; "Why Doctors Disagree," F. L. Van Sickle.

Union Medical Association.-The one hundred and tenth quarterly session of the Union Medical Association of Northwest- 